\title{
Article \\ Systematical Study of the Basic Properties of Surface Acoustic Wave Devices Based on ZnO and GaN Multilayers
}

\author{
Junyao Shen D, Sulei Fu*, Rongxuan Su, Huiping Xu, Fei Zeng, Cheng Song and Feng Pan *
}

check for

updates

Citation: Shen, J.; Fu, S.; Su, R.; Xu,

H.; Zeng, F.; Song, C.; Pan, F.

Systematical Study of the Basic

Properties of Surface Acoustic Wave Devices Based on $\mathrm{ZnO}$ and $\mathrm{GaN}$ Multilayers. Electronics 2021, 10, 23. https://doi.org/10.3390/electronics 10010023

Received: 28 November 2020 Accepted: 23 December 2020 Published: 25 December 2020

Publisher's Note: MDPI stays neutral with regard to jurisdictional clai$\mathrm{ms}$ in published maps and institutional affiliations.

Copyright: $(\odot 2020$ by the authors. Licensee MDPI, Basel, Switzerland. This article is an open access article distributed under the terms and conditions of the Creative Commons Attribution (CC BY) license (https:// creativecommons.org/licenses/by/ $4.0 /)$.
Key Laboratory of Advanced Materials (MOE), School of Materials Science and Engineering, Tsinghua University, Beijing 100084, China; sjy17@mails.tsinghua.edu.cn (J.S.); srx18@mails.tsinghua.edu.cn (R.S.); xhp19@mails.tsinghua.edu.cn (H.X.); zengfei@mail.tsinghua.edu.cn (F.Z.); songcheng@mail.tsinghua.edu.cn (C.S.)

* Correspondence: fusulei@mail.tsinghua.edu.cn (S.F.); panf@mail.tsinghua.edu.cn (F.P.)

\begin{abstract}
Recently, surface acoustic wave (SAW) devices based on layered structures are a popular area of research. Multilayered structures, including $\mathrm{ZnO}$ and $\mathrm{GaN}$, have shown great performance and can be applied in diverse fields. Meanwhile, thin films, such as AlGaN and n-ZnO, can be added to these structures to form a 2-D electron gas (2DEG) which makes the devices tunable. This work systematically studies the basic properties of SAW devices based on $\mathrm{ZnO}$ and GaN multilayers via COMSOL Multiphysics. The sorts of structures with different crystal orientations are simulated, and various acoustic modes are considered. Results show that a range of phase velocity from about $2700 \mathrm{~m} / \mathrm{s}$ to $6500 \mathrm{~m} / \mathrm{s}$ can be achieved, and devices based on $\mathrm{ZnO}$ and GaN multilayers can meet the requirements of the electromechanical coupling coefficient from about 0 to $7 \%$. Every structure's unique properties are valuable for diverse applications. For example, c-ZnO/c-GaN/c-sapphire structure can be used for high-frequency and large-bandwidth SAW devices, while SAW devices based on a-ZnO/a-GaN/r-sapphire and 2DEG are suitable for programmable SAW sensors. This work has great reference value for future research into SAW devices.
\end{abstract}

Keywords: surface acoustic wave; $\mathrm{ZnO} ; \mathrm{GaN} ; 2-\mathrm{D}$ electron gas; multilayer

\section{Introduction}

Surface acoustic wave (SAW) devices have received great attention in the field of wireless communication and sensing applications for decades, because of their small size and reliable performance [1-5]. Conventional SAW devices are fabricated on piezoelectric substrates, such as $\mathrm{LiNbO}_{3}, \mathrm{LiTaO}_{3}$, and quartz. Unfortunately, the acoustic velocities of these piezoelectric substrates are relatively low [6] for high-frequency SAW devices, which is imperative in the 5G era, and performances of SAW devices based on these substrates are hard to optimize because their structures are single. Using layered structures with piezoelectric thin film and substrate with high acoustic velocity is a possible solution.

$\mathrm{ZnO}$, a multi-functional material [7-9], has considerable piezoelectricity, which is suitable for piezoelectric thin film in SAW devices. Plenty of research about SAW devices based on $\mathrm{ZnO}$ thin film and substrates with high acoustic velocities has been published. High frequency can be obtained in $\mathrm{ZnO} /$ diamond or the $\mathrm{ZnO} / \mathrm{SiC}$ structure as the acoustic velocities of diamond and $\mathrm{SiC}$ are extremely high [10-12]. However, diamond and $\mathrm{SiC}$ substrates are expensive, which limits the applications. Compared to diamond and $\mathrm{SiC}$, sapphire wafer is much cheaper, and the acoustic velocity is also very high. Furthermore, the acoustic attenuation loss is low, and the orientation of sapphire substrate is abundant, so $\mathrm{ZnO}$ thin films with different orientations can be grown on various sapphire substrates. These thin films with various SAW properties are appropriate for diverse applications. For example, shear-horizontal (SH) SAW, which can be converted to Love-mode wave $[13,14]$, is suitable for sensing in liquid environments $[15,16]$. A-plane $\mathrm{ZnO}(\mathrm{a}-\mathrm{ZnO})$ can be deposited on r-plane sapphire (r-sapphire) substrate, in which Love-mode SAW can be excited [17]. 
Different types of SAW devices based on c-ZnO/c-sapphire or a- $\mathrm{ZnO} / \mathrm{r}$-sapphire have been theoretically or experimentally studied [18-21], verifying the huge value of the $\mathrm{ZnO} /$ sapphire structure.

Nevertheless, there exists a relatively large mismatch of lattice constants between $\mathrm{ZnO}$ thin film and sapphire substrate, limiting the crystal quality of $\mathrm{ZnO}$ thin film and leading to the propensity of $\mathrm{ZnO}$ to crack [22-24]. A promising solution is using $\mathrm{GaN}$ as a buffer layer because the crystal structure types of $\mathrm{ZnO}$ and $\mathrm{GaN}$ are both hexagonal and their lattice constants are very close [22-24]. By adopting a-GaN buffer layer, many researchers have successfully deposited high-quality and strongly oriented $\mathrm{ZnO}$ thin film [22-24]. Therefore, $\mathrm{ZnO} / \mathrm{GaN} /$ sapphire multilayered structure is appropriate for SAW devices.

Meanwhile, researchers are pursuing programmable and adaptive applications in wireless communication and sensing systems, so developing tunable SAW devices is necessary. One way to realize tunable SAW devices refers to high electron-mobility transistors (HEMT). The acoustoelectric effect, which is where free carriers in a nearby semiconductor affect the amplitude and phase velocity of SAW [25-27], is used. AlGaAs/GaAs, $\mathrm{AlGaN} / \mathrm{GaN}$ and $\mathrm{n}-\mathrm{ZnO} / \mathrm{GaN}$ heterostructures were introduced into SAW devices and considerable tunabilities were achieved [28-31]. This kind of tunable device can be treated as adding one thin layer of $\mathrm{AlGaN}$ or $\mathrm{n}-\mathrm{ZnO}$ into the normal $\mathrm{ZnO} / \mathrm{GaN}$ structure, which is a basic structure of tunable SAW devices. Compared with the films in normal SAW devices, the layer of $\mathrm{AlGaN}$ or $\mathrm{n}-\mathrm{ZnO}$ in the heterostructure is usually very thin, so that the layer does not highly influence the basic SAW performance. Therefore, the basic SAW properties are still decided by the $\mathrm{ZnO} / \mathrm{GaN}$ structure, and the 2-D electron gas (2DEG) makes SAW devices tunable. Analyzing the basic $\mathrm{ZnO} / \mathrm{GaN}$ structure is the foundation.

Former analysis shows that structures with $\mathrm{ZnO}$ and $\mathrm{GaN}$ multilayers are of great value in high-frequency SAW devices, SAW sensors, tunable SAW devices, and so on. However, there are still some valuable structures with $\mathrm{ZnO}$ and $\mathrm{GaN}$ multilayers which have not been proposed and studied. Meanwhile, a study of basic SAW properties, which covers as many structures and wave modes as possible, is helpful for future research. In this work, we systematically research the basic properties of SAW devices based on $\mathrm{ZnO}$ and $\mathrm{GaN}$ multilayers including a-ZnO/a-GaN, a-ZnO/a-GaN/r-sapphire, c-ZnO/c-GaN, $\mathrm{c}-\mathrm{ZnO} / \mathrm{c}-\mathrm{GaN} / \mathrm{c}-\mathrm{sapphire}$, and c- $\mathrm{ZnO} / \mathrm{SiN}_{\mathrm{x}} / \mathrm{GaN}$, etc. These structures are all feasible to be fabricated in reality according to the former research [17-24,32]. Basic characteristics of Rayleigh-mode waves, Sezawa-mode waves, and Love-mode waves, which are appropriate for various applications, have been studied. This work is a reference for research about diverse SAW devices based on $\mathrm{ZnO}$ and $\mathrm{GaN}$ multilayers in the future.

\section{Methods}

All the structures are theoretically studied by the finite element method (FEM) via COMSOL Multiphysics software. Models with only one period and side face, where periodic boundary condition is set, are simulated. One of the electrodes is electrically grounded and the other one is terminal. The Euler angle $(\alpha, \beta, \gamma)$ which describes three successive rotations can achieve any spatial orientations. C-plane orientation, also known as (0001) plane orientation, is the normal one, so the corresponding Euler angle is $(0,0,0)$, which means that the local coordinate systems do not need to be rotated. A-plane is $(11 \overline{2} 0)$ plane. To obtain a-plane, the Euler angle of $\left(\alpha, 90^{\circ}, 0^{\circ}\right)$ should be set. Two-dimensional (2D) models are used in the simulation of devices based on c- $\mathrm{ZnO}$ or c-GaN because the rotation is unnecessary and the displacement in the transverse direction is negligible. We use three-dimensional (3D) model to simulate devices based on a- $\mathrm{ZnO}$, and the Euler angle of $\left(90^{\circ}, 57.6^{\circ}, 150^{\circ}\right)$ is defined to achieve sapphire substrate with r-plane [17]. The Euler angles of $\left(0^{\circ}, 90^{\circ}, 0^{\circ}\right)$ and $\left(90^{\circ}, 90^{\circ}, 0^{\circ}\right)$ corresponds to the a-ZnO or a-GaN with propagation directions of [1100] and [0001], respectively [17]. The material constants are cited from references $[33,34]$ and the material library in COMSOL. 
In this work, $h$ and $\lambda$ stand for the thickness and the wavelength, respectively. The phase velocity $\left(v_{p}\right)$ and the electromechanical coupling coefficient $\left(K^{2}\right)$ are calculated from:

$$
\begin{aligned}
v_{\mathrm{p}} & =\frac{\left(f_{\mathrm{r}}+f_{\mathrm{a}}\right) \times \lambda}{2} \\
K^{2} & =\frac{\pi f_{\mathrm{r}} /\left(2 f_{\mathrm{a}}\right)}{\tan \left[\pi f_{\mathrm{r}} /\left(2 f_{\mathrm{a}}\right)\right]}
\end{aligned}
$$

where $f_{\mathrm{r}}$ is the resonance frequency and $f_{\mathrm{a}}$ is the anti-resonance frequency $[35,36]$. Al is chosen as the material of electrodes in this work and the thicknesses of the electrodes are all $0.08 \lambda$. All the parameters adopted in the FEM studies are shown in Table 1.

Table 1. Parameters adopted in the FEM studies.

\begin{tabular}{cccc}
\hline Items & Details & Items & Details \\
\hline Number of electrodes & 2 & Shape of unit cell & $\begin{array}{c}\text { Quadrangle or } \\
\text { quadrangular prism }\end{array}$ \\
\hline $\begin{array}{c}\text { Thickness of } \\
\text { electrodes }\end{array}$ & $0.08 \lambda$ & Width of unit cell & Less than $0.2 \lambda$ \\
\hline Terminal voltage & $1 \mathrm{~V}$ & Height of unit cell at surface & Less than $0.2 \lambda$ \\
\hline Boundary condition & Periodic & Depth of 3D models & $0.25 \lambda$ \\
\hline
\end{tabular}

To accurately study the propagation properties, we show displacement curves and deformation shapes of the excited SAW. Deformation shapes intuitively describe vibration states. Displacement $(u)$ has three components, including $u_{x}, u_{y}$, and $u_{z}$. The displacement curve shows the normalized displacement at every point on an imaginary perpendicular line passing straight through the whole model from the middle of one electrode in the anti-symmetric state. For three-dimensional models, $u_{x}, u_{y}$, and $u_{z}$ are all shown in the displacement curves, while only $u_{x}$ and $u_{z}$ are depicted for two-dimensional ones.

\section{Results}

At first, SAW devices based on a- $\mathrm{ZnO}$ are studied because different modes of SAW can be used in various propagation directions [17]. When a-GaN substrate is directly adopted or a-GaN thin film is much thicker than the propagation area of SAW, the SAW devices have a- $\mathrm{ZnO} / \mathrm{a}-\mathrm{GaN}$ bilayer structure.

\subsection{Devices Based on $a-\mathrm{ZnO} / \mathrm{a}-\mathrm{GaN}$}

A typical admittance response in the structure shown in Figure $1 \mathrm{a}$ is depicted in Figure $1 \mathrm{~b}$, in which $\lambda$ is $2 \mu \mathrm{m}$ and the $\mathrm{ZnO}$ thickness is $0.8 \lambda$. The frequency of the 0 th mode wave is about $1.3 \mathrm{GHz}$ and that of the 1 st mode wave is about $1.7 \mathrm{GHz}$. To ensure the modes of excited SAW and determine the propagation characteristics, we show the displacement curves and the corresponding deformation shapes in Figure 1c,d. It can be clearly seen that the displacements only focus on the $y$ direction. Considering the $x$ propagation direction, we can identify that the SAW is SH wave. As the phase velocity of $\mathrm{GaN}$ is higher than that of $\mathrm{ZnO}$ [37], $\mathrm{ZnO}$ can be regarded as the waveguiding layer of the $\mathrm{SH}-\mathrm{SAW}$. We can more precisely call it Love-mode wave. Figure 1c shows the displacement curves, the deformation shapes in anti-symmetric (anti-sym) and symmetric (sym) states of the SAW corresponding to the 0th mode in Figure 1b. The displacement reaches its maximum at the surface and reduces dramatically beneath the surface. The wave only penetrates about $2 \lambda$ below the surface. For higher order modes, deformation shapes are more complicated. Figure 1d, corresponding to the 1st mode in Figure 1b, shows that the penetration is deeper, but the wave still focuses on the surface. 
(a)
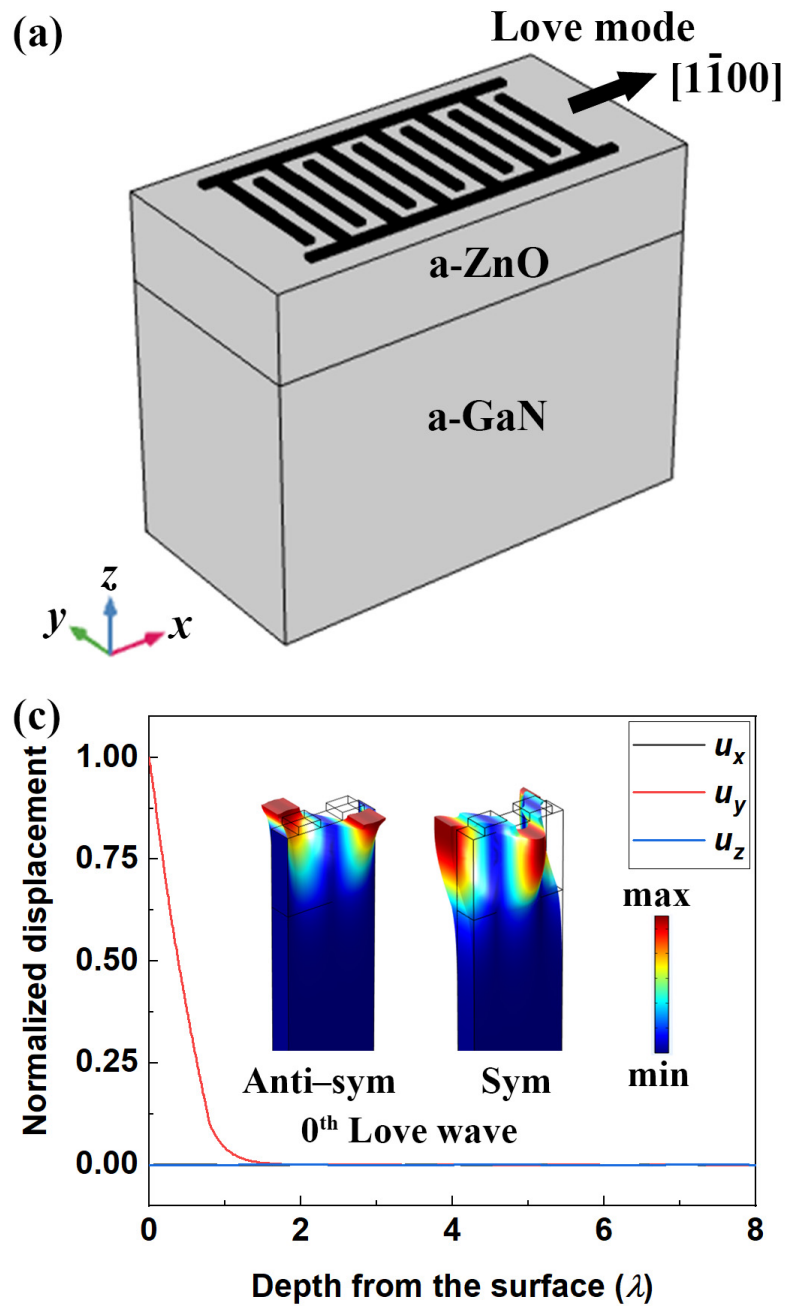
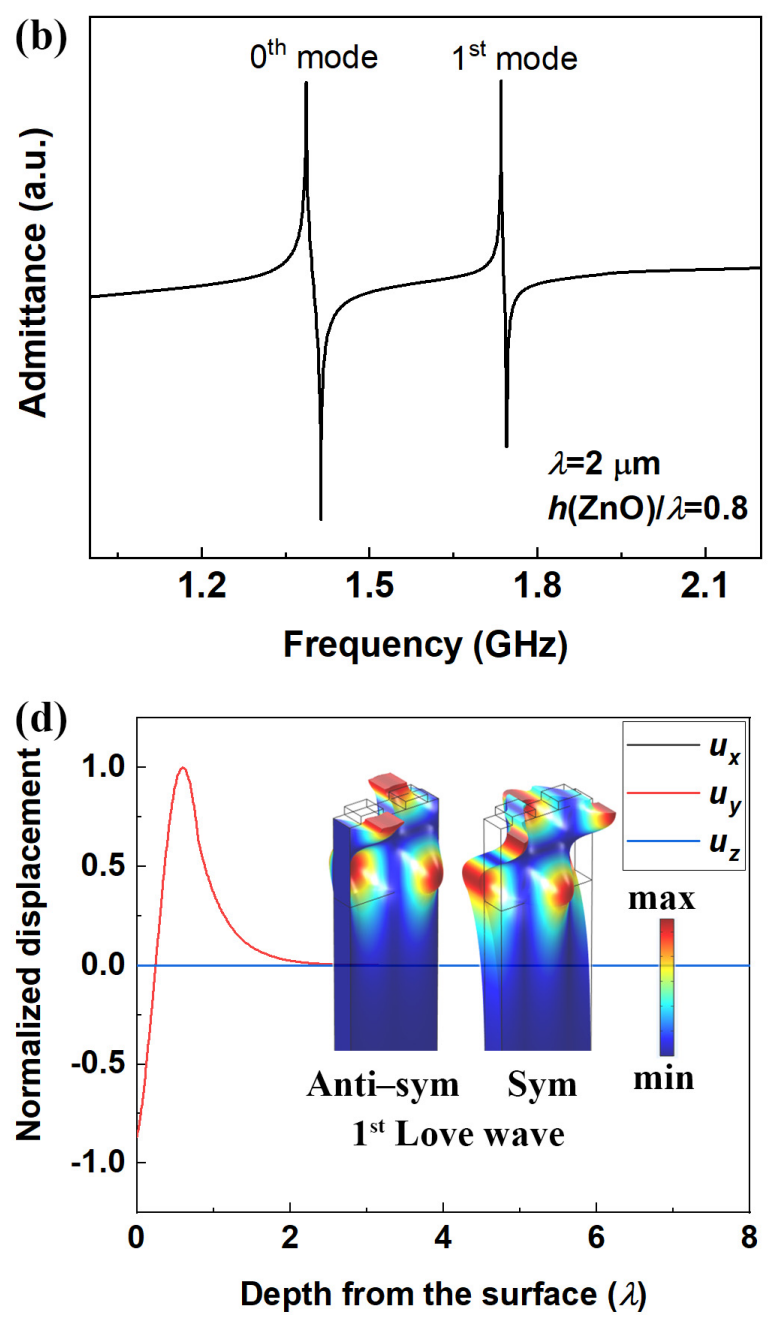

Figure 1. A typical admittance response (b) and its corresponding displacement curves and deformation shapes (c,d) of the SAW devices based on the a-ZnO/a-GaN structure (a) where Love-mode waves are excited.

When the propagation direction rotates $90^{\circ}$, the responses change totally, as shown in Figure 2. Figure $2 \mathrm{~b}$ depicts a typical admittance curve, in which the 1 st mode response becomes weak. Figure 2c,d show that the wave only vibrates in the $X Z$ plane and in a shape of ellipse, so Rayleigh-mode wave is excited. 0th mode wave only propagates in the surface region with the depth about $2 \lambda$, as in Figure $2 c$, but the 1 st mode wave penetrates deeply. A large amount of energy loses when the 1st mode Rayleigh wave is excited, leading to a weak response.

The $v_{p}$ and $K^{2}$ dispersion patterns of the Love-mode waves in Figure 1 are shown in Figure $3 a$. The values of $v_{p}$ of the first two orders both decrease monotonically with the increase of the $\mathrm{ZnO}$ thickness because the smaller phase velocity of a- $\mathrm{ZnO}$. The values of $K^{2}$ of 0 th mode Love wave are quite large, and a maximum value which is larger than $5 \%$ appears at $h(\mathrm{ZnO}) / \lambda=0.3$ when the $v_{\mathrm{p}}$ is about $3000 \mathrm{~m} / \mathrm{s}$. The cutoff point of the $1 \mathrm{st}$ mode Love wave is at about $h(\mathrm{ZnO}) / \lambda=0.5$. The values of $v_{\mathrm{p}}$ of the 1 st mode wave are relatively large, but the values of $K^{2}$ are smaller compared with those of the 0th mode. The maximum value of $K^{2}$ is still smaller than $2 \%$. Figure $3 b$ shows the properties of the Rayleigh-mode waves in Figure 2 as functions of the $\mathrm{ZnO}$ thickness. The $v_{\mathrm{p}}$ of each mode also decreases when the $\mathrm{ZnO}$ thickness is larger. In the meantime, the values of $K^{2}$ of the Rayleigh-mode waves are smaller than those of the Love-mode waves in Figure 3a. When the $\mathrm{ZnO}$ thickness is larger than $1 \lambda$, the values of $K^{2}$ of the 0 th mode Rayleigh wave stabilize at the value about $1.9 \%$ and the values of $v_{p}$ stabilize around $2700 \mathrm{~m} / \mathrm{s}$. The 
$K^{2}$ of the 1st mode wave is quite small, just as expected, and the cutoff point is at about $h(\mathrm{ZnO}) / \lambda=0.7$.

(a)
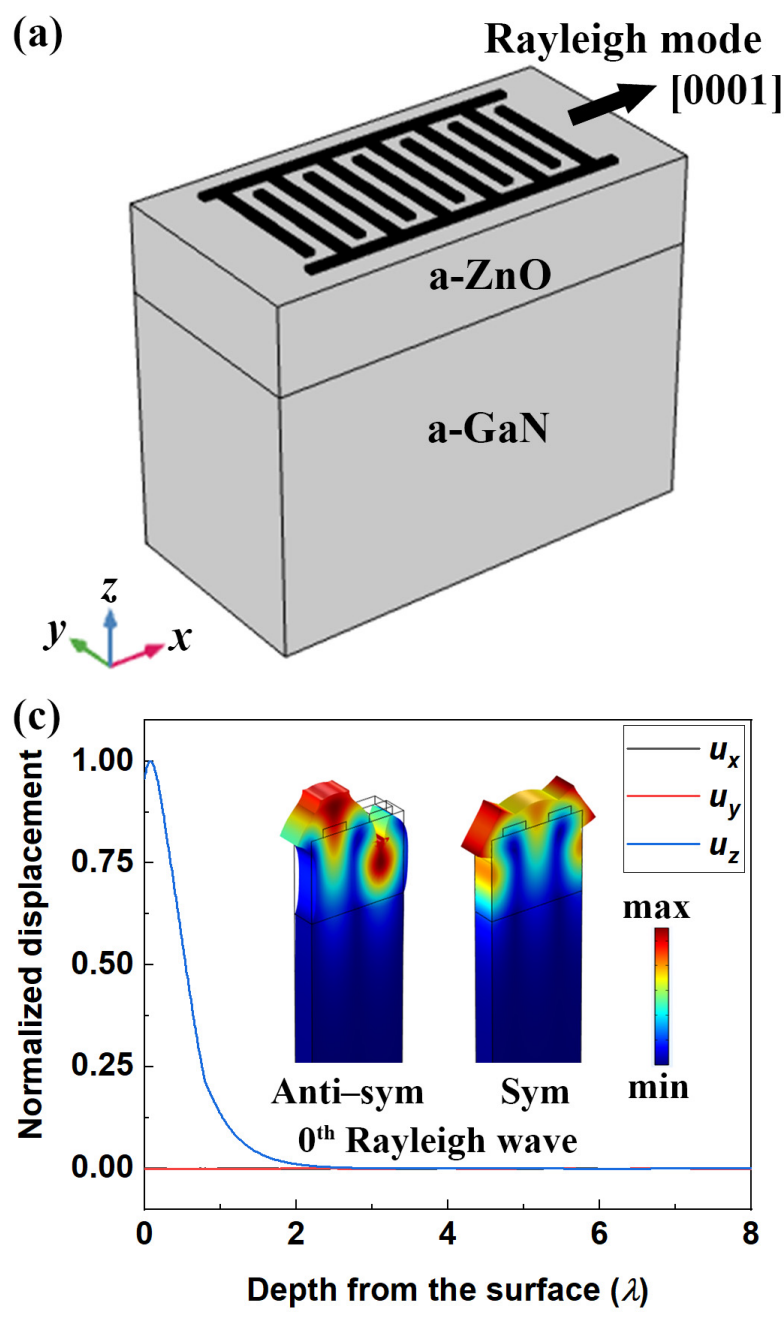
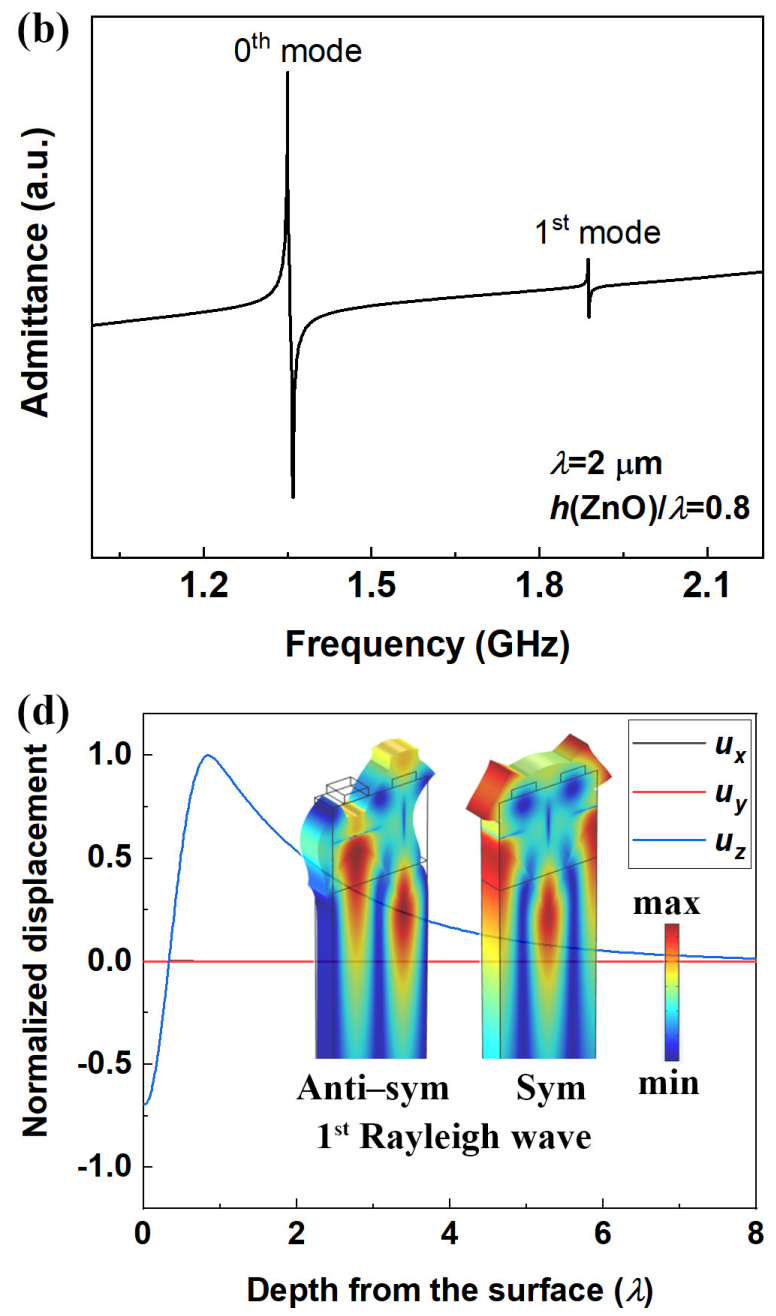

Figure 2. A typical admittance response (b) and its corresponding displacement curves and deformation shapes (c,d) of the SAW devices based on the a- $\mathrm{ZnO} / \mathrm{a}-\mathrm{GaN}$ structure (a) where Rayleigh-mode waves are excited.
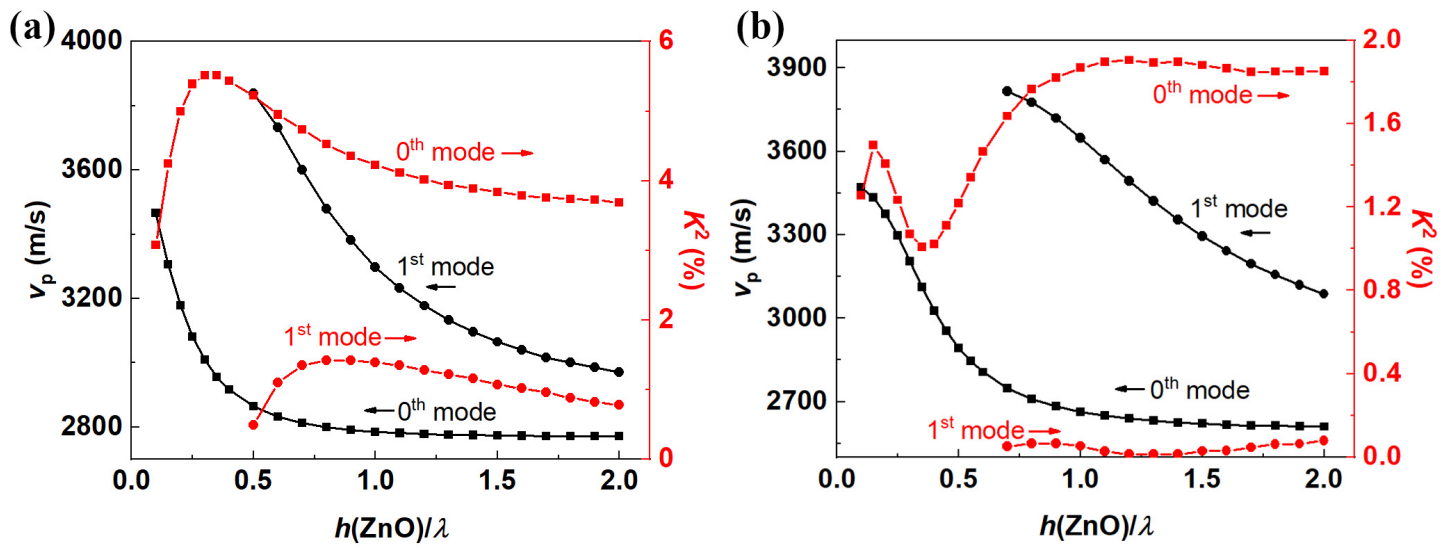

Figure 3. $v_{\mathrm{p}}$ and $K^{2}$ of Love-mode waves (a) and Rayleigh-mode waves (b) as functions of $h(\mathrm{ZnO})$ in the SAW devices based on the $\mathrm{a}-\mathrm{ZnO} / \mathrm{a}-\mathrm{GaN}$ structure. 


\subsection{Devices Based on $a-Z n O / a-G a N / r-S a p p h i r e$}

When the thickness of GaN thin film is comparable to the wavelength or even thinner, the influence from the sapphire substrate must be considered, so the structure shown in Figure $4 \mathrm{a}$ is studied. A typical admittance curve, in which $\lambda, h(\mathrm{ZnO})$ and $h(\mathrm{GaN})$ are $2 \mu \mathrm{m}, 0.5 \lambda$ and $0.5 \lambda$, respectively, is shown in Figure $4 \mathrm{~b}$. The frequency of the 0th mode wave reaches about $1.4 \mathrm{GHz}$ and the 1st mode wave with the frequency of around $2 \mathrm{GHz}$ is excited. The corresponding displacement curves and deformation shapes are shown in Figure $4 c, d$ where the vibration states are similar to those in Figure $1 c, d$, so the SAW can be identified as the Love-mode wave. As the sapphire substrate with higher acoustic velocity has stronger effect of wave confinement than $\mathrm{GaN}$, the propagation region in the $\mathrm{a}-\mathrm{ZnO} / \mathrm{a}-\mathrm{GaN} / \mathrm{r}$-sapphire structure is shallower than that in the a-ZnO/a-GaN structure, which can be seen in Figures 1 and 4 .

The values of $v_{p}$ and $K^{2}$ of the Love-mode waves in Figure 4 are calculated as functions of $h(\mathrm{ZnO})$ and $h(\mathrm{GaN})$, and the results are shown in Figure 5. The values of $v_{\mathrm{p}}$ of both modes decrease clearly with the increasing $h(\mathrm{GaN})$, because the acoustic velocity of $\mathrm{GaN}$ is smaller than that of sapphire. The values of $K^{2}$ of 0th mode are not highly influenced by the $\mathrm{GaN}$ thickness, which can be seen in Figures $3 \mathrm{a}$ and 5. It proves that the $\mathrm{ZnO}$ layer mainly converts the energy during Love wave excitation, and the GaN layer and the sapphire layer both only propagate the wave. Nevertheless, the response of 1st mode wave is a little different from that in the a- $\mathrm{ZnO} / \mathrm{a}-\mathrm{GaN}$ structure which has a cutoff point. Even when the $\mathrm{ZnO}$ thickness equals $0.1 \lambda$, 1st mode Love SAW is still excited, owing to the strong effect of wave confinement from the sapphire substrate. The values of $K^{2}$ of the 1st mode are still smaller than $2 \%$, which is same as the a- $\mathrm{ZnO} / \mathrm{a}-\mathrm{GaN}$ structure. On the other hand, the values of $v_{p}$ of both modes decrease and approach to the acoustic velocity of $\mathrm{ZnO}$ with the thickness increase of $\mathrm{ZnO}$ thin film. The $K^{2}$ of the 0 th mode increases at first and then decreases when the $\mathrm{ZnO}$ film is thickened, causing a maximum value close to $6 \%$ at $h(\mathrm{ZnO}) / \lambda=0.3$.

SAW devices based on the a- $\mathrm{ZnO} / \mathrm{a}-\mathrm{GaN} / \mathrm{r}$-sapphire structure with the propagation direction of [0001] have not been studied, because we believe that they are not actually valuable. There are too many SAW responses in these devices and these responses are influenced with each other. Moreover, if we want to obtain Rayleigh wave response, fabricating SAW devices based on c- $\mathrm{ZnO}$ is a great choice.

\subsection{Devices Based on $\mathrm{c}-\mathrm{ZnO} / \mathrm{c}-\mathrm{GaN}$}

The propagation direction of devices based on c-ZnO does not highly influence the properties of SAW, so we only study the devices based on c-ZnO with one normal propagation direction. Figure $6 \mathrm{a}$ shows the basic c- $\mathrm{ZnO} / \mathrm{c}-\mathrm{GaN}$ structure and Figure $6 \mathrm{~b}$ depicts a typical admittance response when the $\lambda$ is $2 \mu \mathrm{m}$ and the $\mathrm{ZnO}$ thickness is $0.8 \lambda$. The frequencies of the 0th mode and 1st mode are about $1.35 \mathrm{GHz}$ and $1.85 \mathrm{GHz}$, respectively, close to those of Love-mode waves in devices based on the a- $\mathrm{ZnO} / \mathrm{a}-\mathrm{GaN}$ structure. Figure $6 \mathrm{c}$ shows the displacement curves and the deformation shapes of the 0th mode wave and Figure $6 \mathrm{~d}$ shows the ones of the 1 st mode. Two-dimensional models are simulated for devices based on c- $\mathrm{ZnO}$, as we discussed before, so only the curves of $u_{x}$ and $u_{z}$ are drawn in Figure $6 c, d$. The deformation shapes and displacement curves indicate that the responses come from the 0th mode Rayleigh wave and the 1st mode Rayleigh wave. The 0th mode penetrates about $2 \lambda$ deep, but 1st mode deeper than $4 \lambda$. The 1st mode Rayleigh wave is still a stable SAW because it is non-leaky, even though it penetrates a lot. 
(a)

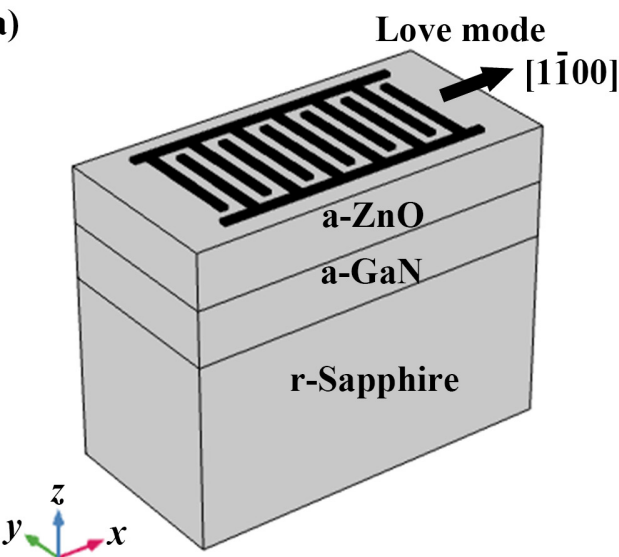

(c)

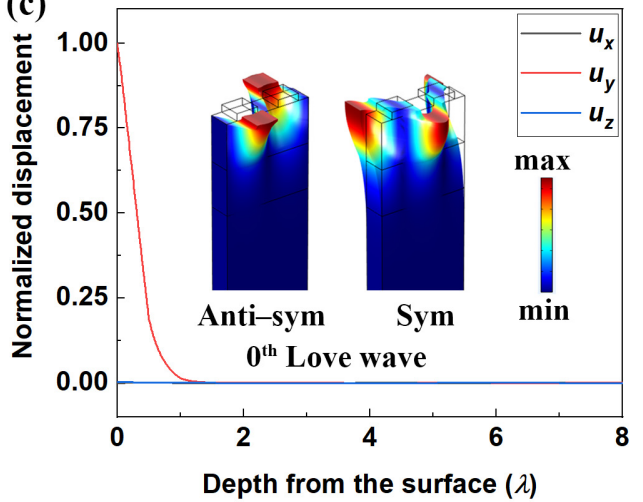

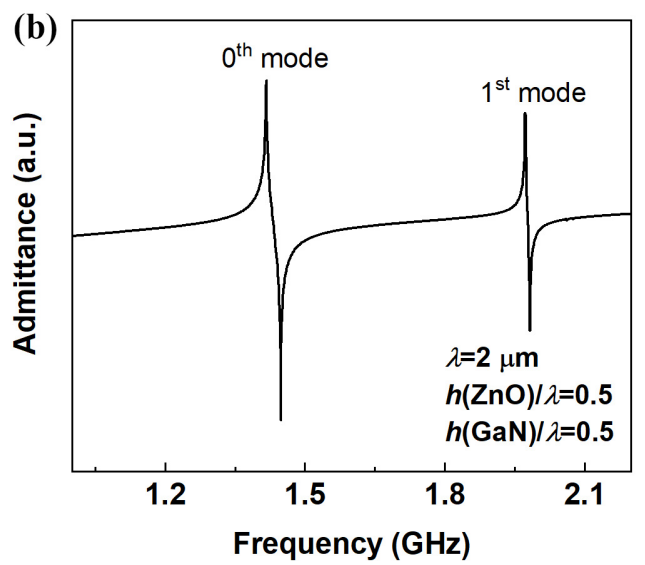

(d)

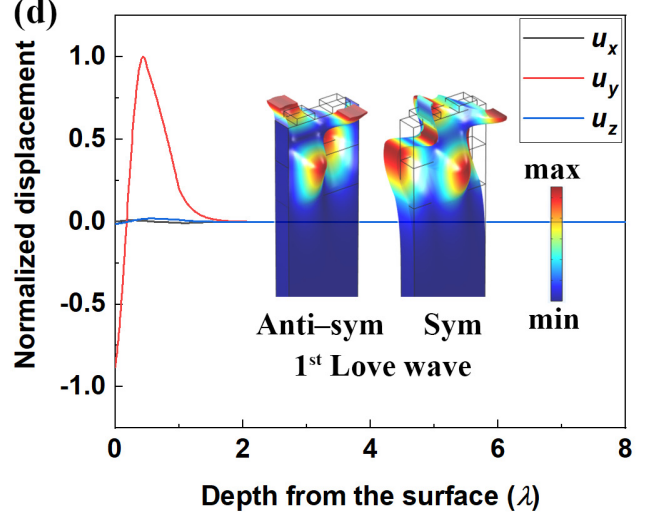

Figure 4. A typical admittance response (b) and its corresponding displacement curves and deformation shapes $(\mathbf{c}, \mathbf{d})$ of the $\mathrm{SAW}$ devices based on the $\mathrm{a}-\mathrm{ZnO} / \mathrm{a}-\mathrm{GaN} / \mathrm{r}$-sapphire structure (a) where Love-mode waves are excited.
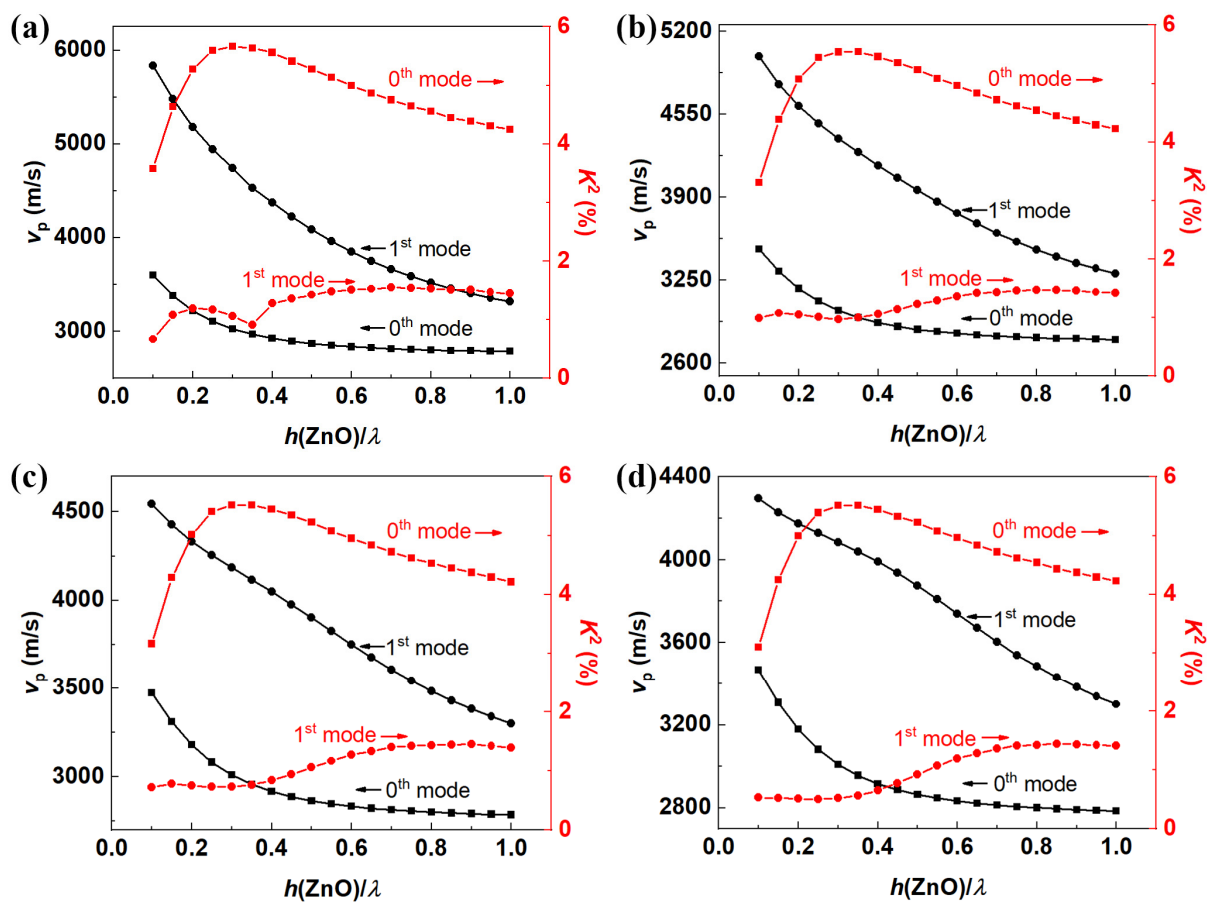

Figure 5. $v_{\mathrm{p}}$ and $\mathrm{K}^{2}$ of Love-mode waves as functions of $h(\mathrm{ZnO})$ in the SAW devices based on the a-ZnO/a-GaN/r-sapphire structure with $h(\mathrm{GaN})$ of $0.25 \lambda(\mathbf{a}), 0.5 \lambda(\mathbf{b}), 0.75 \lambda(\mathbf{c})$ and $1.0 \lambda(\mathbf{d})$. 
(a)
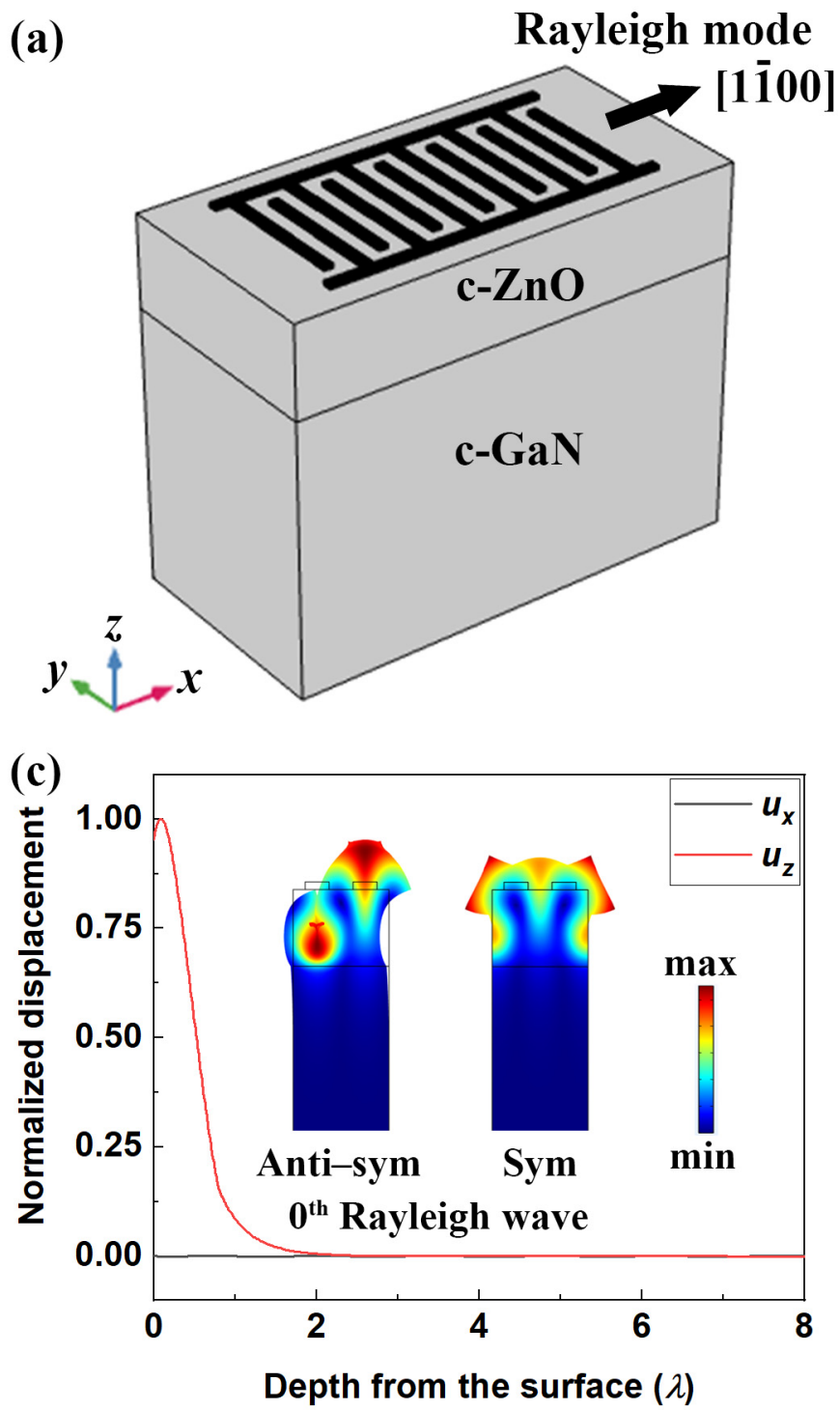
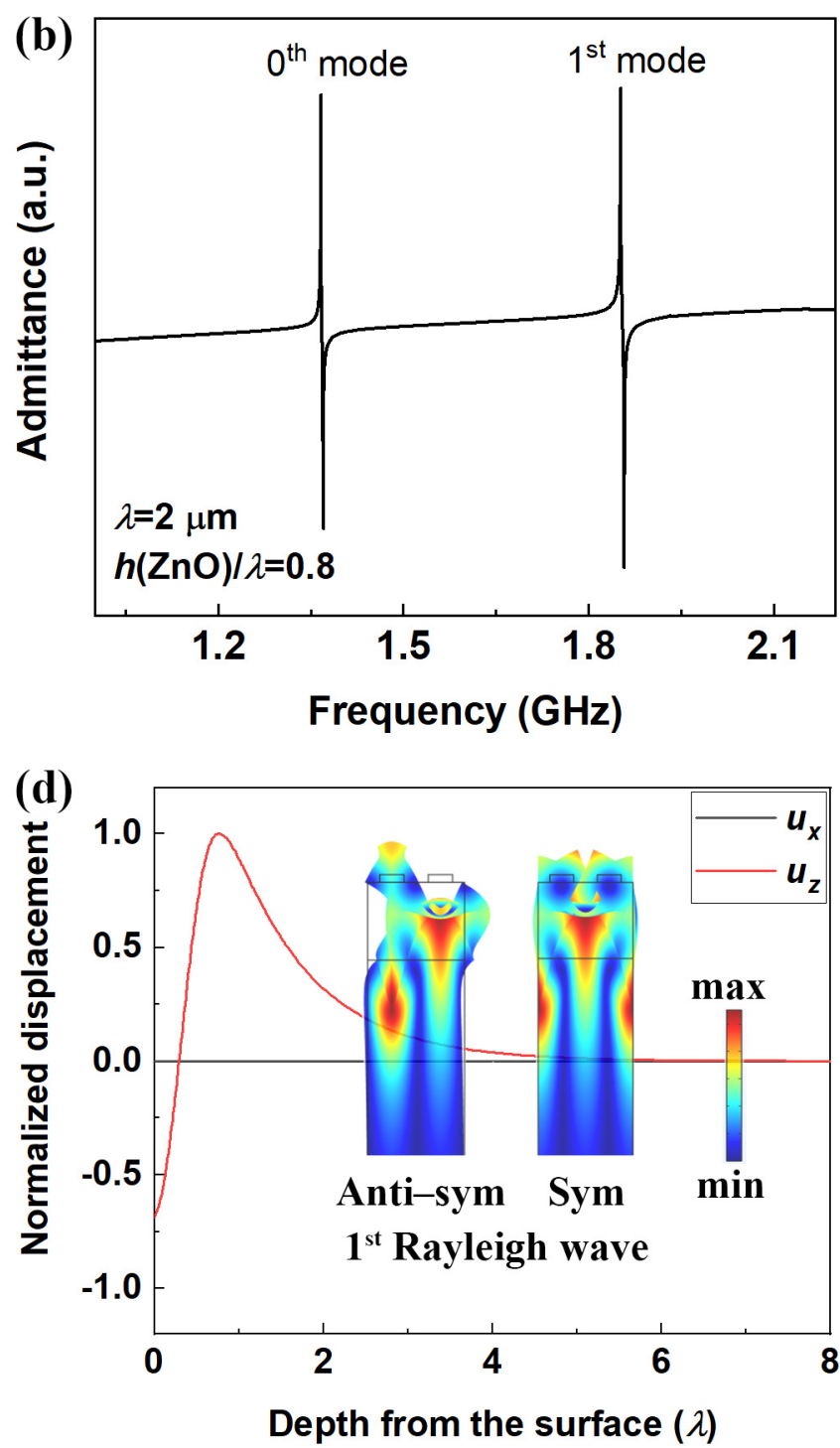

Figure 6. A typical admittance response (b) and its corresponding displacement curves and deformation shapes (c,d) of the SAW devices based on the $\mathrm{c}-\mathrm{ZnO} / \mathrm{c}-\mathrm{GaN}$ structure (a) where Rayleigh-mode waves are excited.

To systematically study the structure in Figure $6 \mathrm{a}$, we calculate the $v_{\mathrm{p}}$ and $K^{2}$ of the Rayleigh-mode waves in devices with the variation of $h(\mathrm{ZnO})$ and depict the results in Figure 7 . With the increase of the $\mathrm{ZnO}$ thickness, the values of $v_{\mathrm{p}}$ of two modes decrease, same as the tendencies in Figures 3 and 5 for the same reason. When $h(\mathrm{ZnO})$ rises, the $K^{2}$ of the 0th mode decreases at first and then increases until reaching the maximum value of about $1.05 \%$. For the 0 th mode waves in the devices with $h(\mathrm{ZnO})$ larger than $1.5 \lambda$, the values of $v_{\mathrm{p}}$ and $K^{2}$ stabilize at about $2700 \mathrm{~m} / \mathrm{s}$ and $1.05 \%$, respectively. For the 1 st mode wave, there exists a cutoff point at about $h(\mathrm{ZnO}) / \lambda=0.5$ and exists a maximum value of about $0.8 \%$ at about $h(\mathrm{ZnO}) / \lambda=0.9$. The values of $K^{2}$ are relatively small in the devices based on the structure in Figure 6a, which can be clearly seen in Figure 7. 


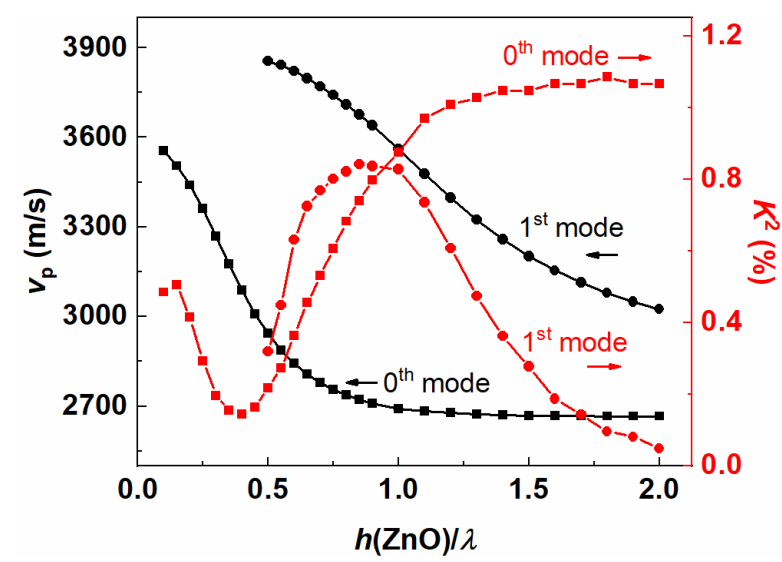

Figure 7. $v_{\mathrm{p}}$ and $K^{2}$ of Rayleigh-mode waves as functions of $h(\mathrm{ZnO})$ in the SAW devices based on the $\mathrm{c}-\mathrm{ZnO} / \mathrm{c}-\mathrm{GaN}$ structure.

\subsection{Devices Based on $\mathrm{c}-\mathrm{ZnO} / \mathrm{c}-\mathrm{GaN} / \mathrm{c}$-Sapphire}

Now we consider the situation in which $\mathrm{GaN}$ is a thin film. The c-ZnO/c-GaN/csapphire structure is depicted in Figure 8a and a typical admittance curve is shown in Figure $8 \mathrm{~b}$. When the $\lambda, h(\mathrm{ZnO})$ and $h(\mathrm{GaN})$ equal $2 \mu \mathrm{m}, 0.5 \lambda, 0.5 \lambda$, respectively, the 0 th mode response is excited at the frequency of about $1.5 \mathrm{GHz}$ and the 1st mode at about 2.2 GHz. The corresponding deformation shapes and normalized displacement curves are shown in Figure 8c,d. According to the previous analysis, Rayleigh-mode waves are excited in this structure. Same as the wave in Figure $6 c$, the 0th mode wave in Figure $8 c$ also propagates in the region near the surface. However, if we compare Figure $6 \mathrm{~d}$ with Figure $8 d$, differences appear. GaN layer cannot highly confine the wave because the acoustic velocities of $\mathrm{GaN}$ and $\mathrm{ZnO}$ are close, resulting in obvious displacements even at $4 \lambda$ beneath the surface. The acoustic velocity of sapphire is much larger, so it dramatically confines the 1st mode wave. The so-called "slow-on-fast" structure makes the 1st mode Rayleigh wave become a confined mode which is specifically called Sezawa-mode [38-40].

The $v_{p}$ and $K^{2}$ dispersion patterns of the 0th mode Rayleigh wave in Figure 8 are shown in Figure $9 \mathrm{a}, \mathrm{b}$. The values of $v_{\mathrm{p}}$ decrease monotonically with the increase of $h(\mathrm{ZnO})$, while those of $K^{2}$ decrease at first and then increase. These tendencies are similar to those of the same mode in Figure 7 . In the devices with the $\mathrm{ZnO}$ film thinner than about $0.8 \lambda$, the values of $v_{p}$ decrease and approach to the values of the same mode in Figure 7 with the increasing thickness of GaN. It verifies that the sapphire substrate has the function of frequency improvement. Still in these devices, the values of $K^{2}$ increase and get close to those in Figure 7 when the GaN thickness is thickened from $0.25 \lambda$ to $1.0 \lambda$. We believe that the GaN which is also a piezoelectric material can convert energy to some extent during the Rayleigh-mode excitation, so thickening GaN helps increase the $K^{2}$ when the $\mathrm{ZnO}$ layer is thin. The $\mathrm{ZnO}$ layer mainly excites and propagates the wave if it is thick, then the values of $v_{\mathrm{p}}$ and $K^{2}$ do not change much with the variation of $h(\mathrm{GaN})$.

The $v_{p}$ and $K^{2}$ of the 1st mode Rayleigh wave (Sezawa-mode wave) as functions of the thicknesses of $\mathrm{ZnO}$ and $\mathrm{GaN}$ are shown in Figure $9 \mathrm{c}, \mathrm{d}$. There is no cutoff point in this structure. The values of $v_{\mathrm{p}}$ and $K^{2}$ both decrease and approach to the values in Figure 7 with the increase of $h(\mathrm{GaN})$, because the GaN layer hampers the sapphire's abilities to improve the $v_{p}$ and confine the wave. When the $\mathrm{ZnO}$ thickness is thickened, the values of $v_{p}$ decrease monotonically, and those of $K^{2}$ increase at first and then decrease. At $h(\mathrm{ZnO}) / \lambda=0.3$ and $h(\mathrm{GaN}) / \lambda=0.25$, the $v_{\mathrm{p}}$ reaches about $5000 \mathrm{~m} / \mathrm{s}$ and the $K^{2}$ is around $4.5 \%$. These two values are much larger than those in the devices based on c- $\mathrm{ZnO} / \mathrm{c}-\mathrm{GaN}$. 
(a)

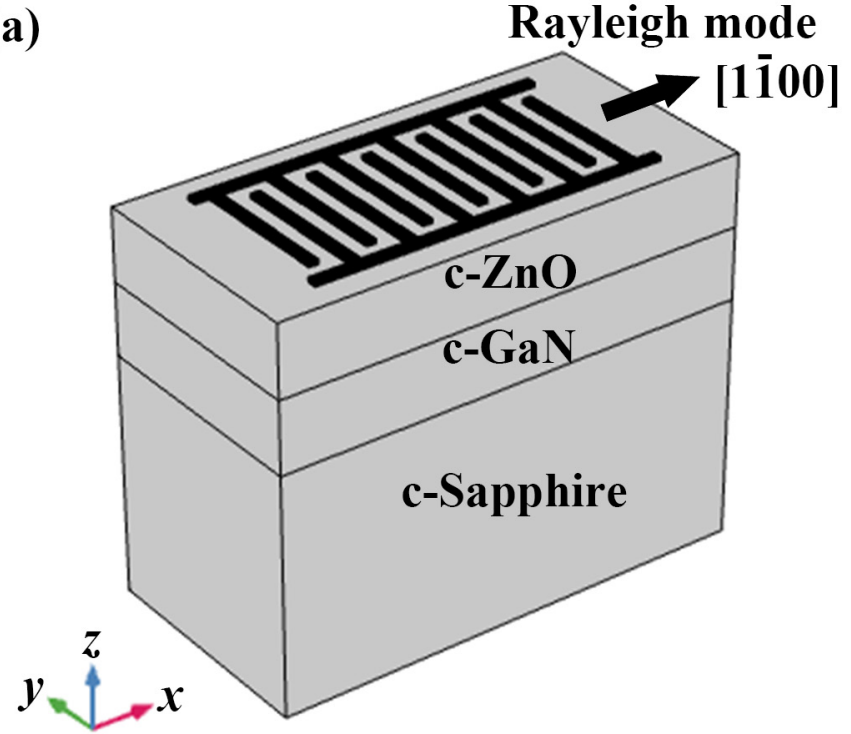

(c)

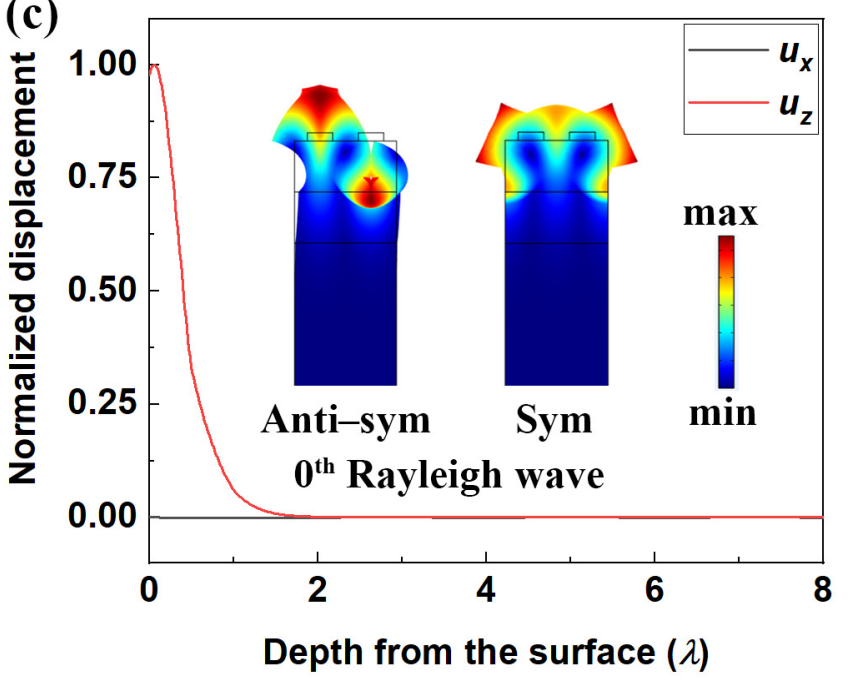

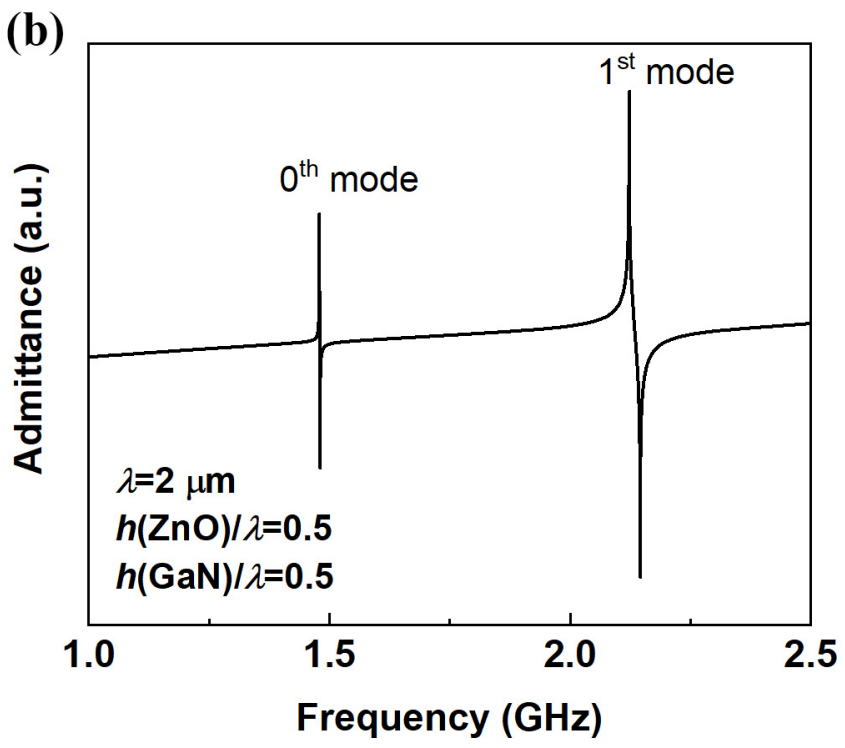

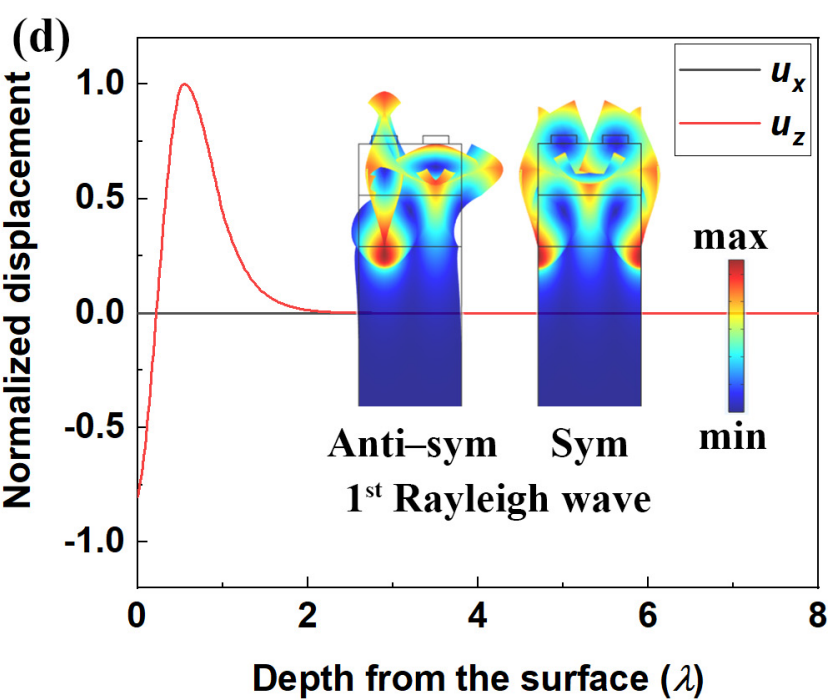

Figure 8. A typical admittance response (b) and its corresponding displacement curves and deformation shapes (c,d) of the SAW devices based on the c-ZnO/c-GaN/c-sapphire structure (a) where 0th Rayleigh-mode wave and 1st Rayleigh-mode wave (Sezawa-mode wave) are excited.

\subsection{Other Devices with Sezawa-Mode Wave}

Sezawa-mode wave has the advantages of high $v_{p}$ and large $K^{2}$, which can be reflected by Figure 9 . Therefore, we further study other four structures with a high-velocity layer $\mathrm{SiN}_{\mathrm{x}}$ between c- $\mathrm{ZnO}$ and $\mathrm{GaN}$, in which the 1st mode Rayleigh wave (Sezawa-mode wave) is excited. The $\mathrm{SiN}_{\mathrm{x}}$ layer is amorphous and the thickness is set as $3 \lambda$ for full function, so the orientation of $\mathrm{GaN}$ is not important. We use c-GaN in the models, but we do not specifically mention it in this part. The admittance responses and the corresponding displacement curves and deformation shapes are similar to those of the c-ZnO/c-GaN/csapphire structure shown in Figure 8, so we do not display them in this part.

The basic SAW device based on $\mathrm{c}-\mathrm{ZnO} / \mathrm{SiN}_{\mathrm{x}} / \mathrm{GaN}$ structure is shown in Figure 10a. Thanks to the existence of $\mathrm{SiN}_{\mathrm{x}}$, the so-called "slow-on-fast" structure forms and the 1st mode Rayleigh wave appears in the form of Sezawa-mode wave. The $v_{p}$ and $K^{2}$ dispersion patterns are shown in Figure 10b. For the 0th mode wave, the values of $v_{p}$ are smaller than $4000 \mathrm{~m} / \mathrm{s}$ and those of $K^{2}$ are no larger than $1 \%$. Nevertheless, the Sezawa-mode wave 
has larger $v_{\mathrm{p}}$ and $K^{2}$. The values of $v_{\mathrm{p}}$ and $K^{2}$ reach about $5200 \mathrm{~m} / \mathrm{s}$ and $4.5 \%$ respectively when the $\mathrm{ZnO}$ thickness is $0.3 \lambda$.
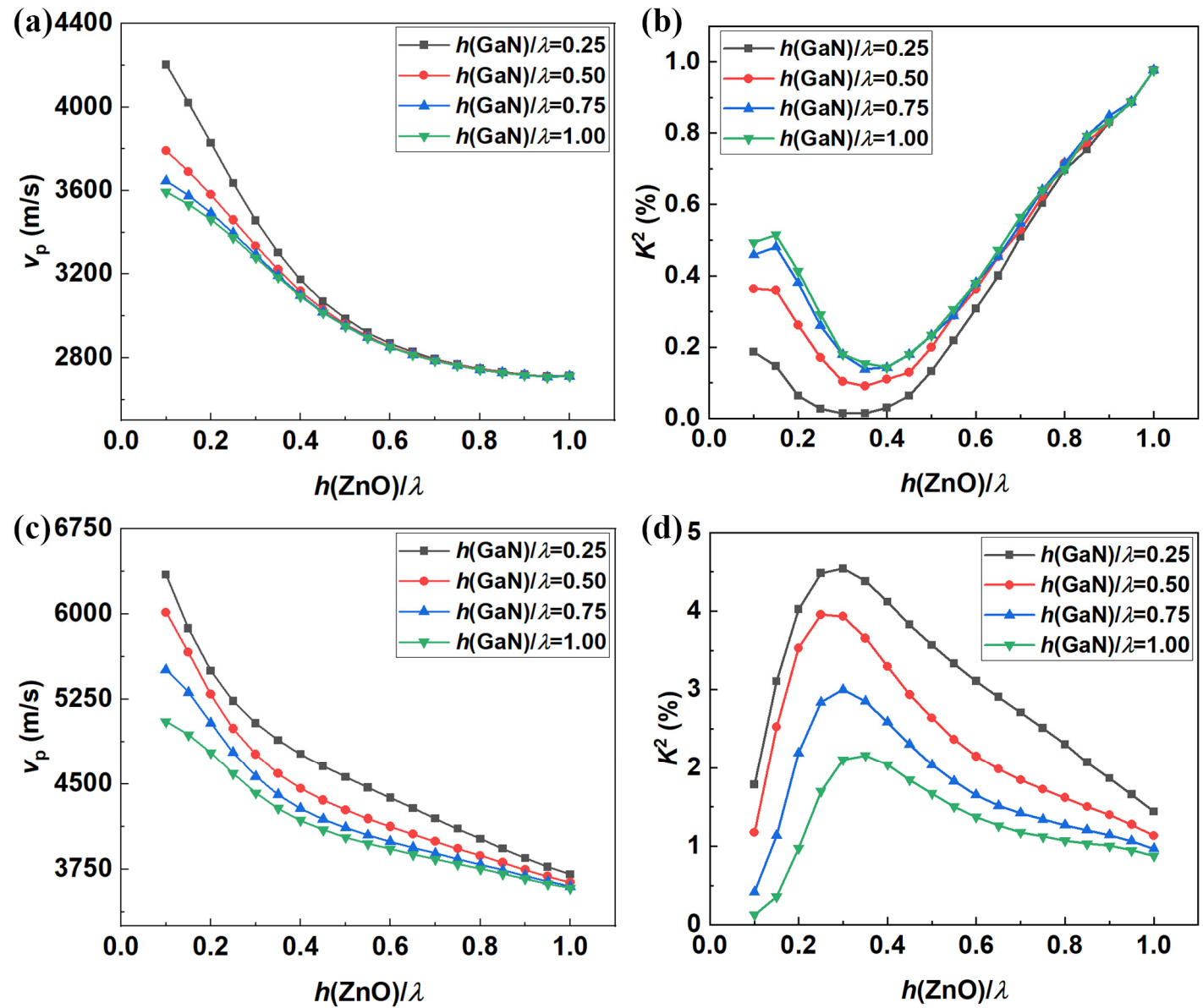

Figure 9. $v_{p}(\mathbf{a})$ and $K^{2}(\mathbf{b})$ of 0th mode Rayleigh wave, $v_{p}(\mathbf{c})$ and $K^{2}(\mathbf{d})$ of 1 st mode Rayleigh wave (Sezawa-mode wave) as functions of $h(\mathrm{ZnO})$ and $h(\mathrm{GaN})$ in the SAW devices based on the $\mathrm{c}-\mathrm{ZnO} / \mathrm{c}-\mathrm{GaN} / \mathrm{c}$-sapphire structure.

Then we study how a short-circuit thin film influences the properties of the Rayleighmode waves, so devices based on the $\mathrm{c}-\mathrm{ZnO} / \mathrm{Al} / \mathrm{SiN}_{\mathrm{x}} / \mathrm{GaN}$ structure shown in Figure $10 \mathrm{c}$ are simulated and the results are depicted in Figure 10d. The thickness of the short-circuit thin film is $0.05 \lambda$. Comparing Figure $10 \mathrm{~b}, \mathrm{~d}$, we can clearly see the difference. The shortcircuit thin film slightly reduces the $v_{\mathrm{p}}$ of two modes, but it rarely affects the $K^{2}$ of the 0th mode. For the devices with very thin $\mathrm{ZnO}$ film, the values of $K^{2}$ of the Sezawa-mode are dramatically increased by the short-circuit thin film. The $K^{2}$ reaches about $7 \%$, which is the largest in this work, at $h(\mathrm{ZnO}) / \lambda=0.2$. Meanwhile, the $v_{\mathrm{p}}$ reaches about $5300 \mathrm{~m} / \mathrm{s}$ which is quite large.

Adopting embedded interdigital transducers (IDT) is another normal modulation for SAW devices, so we study the structure shown in Figure 10e. Considering the current fabrication technique, it is hard to grow $\mathrm{ZnO}$ thin film with no pore and great c-plane orientation between the electrodes, but the amorphous $\mathrm{SiO}_{2}$ thin film can be grown densely owing to the requirements of temperature compensated $\mathrm{SAW}$ devices. Hence, $\mathrm{SiO}_{2}$ is used to fill in the blanks between electrodes, and then the $\mathrm{ZnO}$ layer is prepared on a smooth surface, as shown in Figure 10e. The $v_{p}$ and $K^{2}$ dispersion patterns are shown in Figure 10f which can be compared with Figure 10b. The values of $v_{\mathfrak{p}}$ of two modes in Figure $10 \mathrm{f}$ are slightly decreased but still very close to those in Figure 10b. Embedding IDT can highly increase the $K^{2}$ of the 0 th mode wave, but the 1st mode wave is restricted. When the thickness of $\mathrm{ZnO}$ is $0.5 \lambda$, a 0th mode wave with $K^{2}$ of about $3 \%$ can be obtained. 
(a)

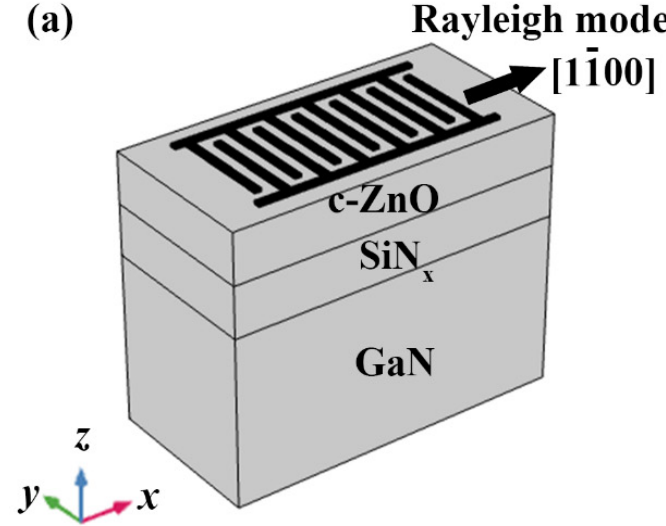

(c)

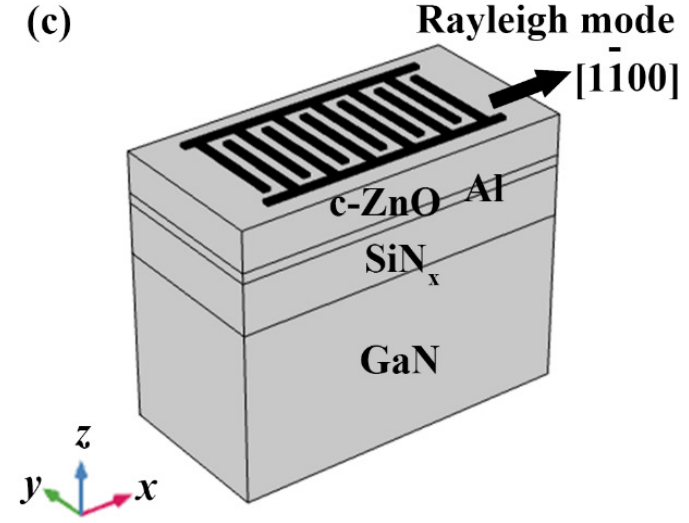

(e)

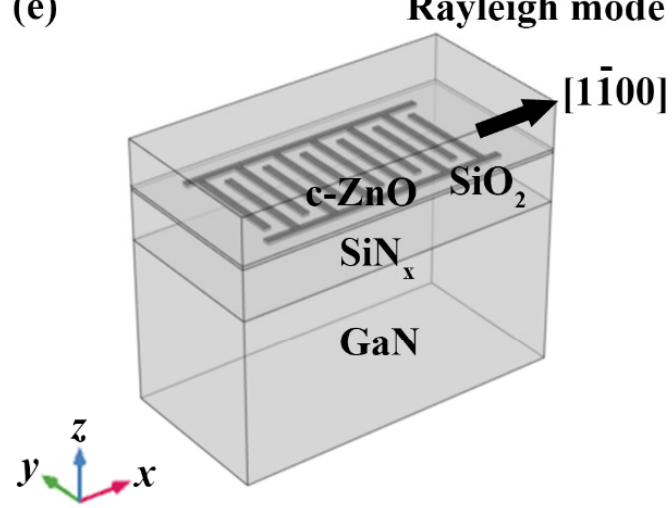

(g)

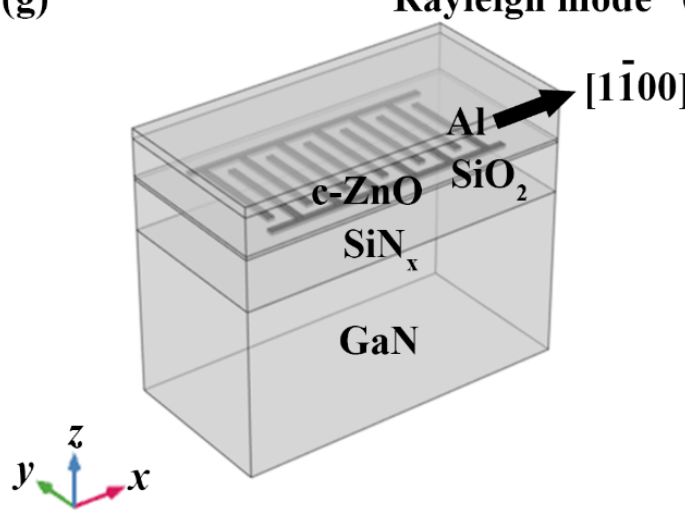

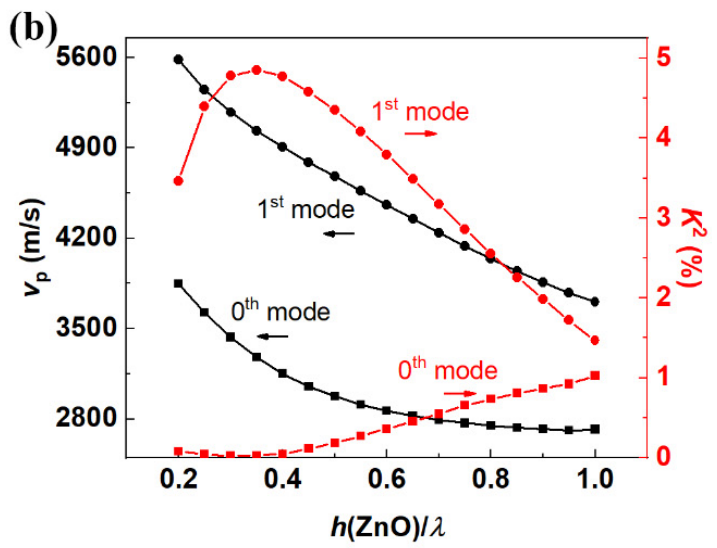
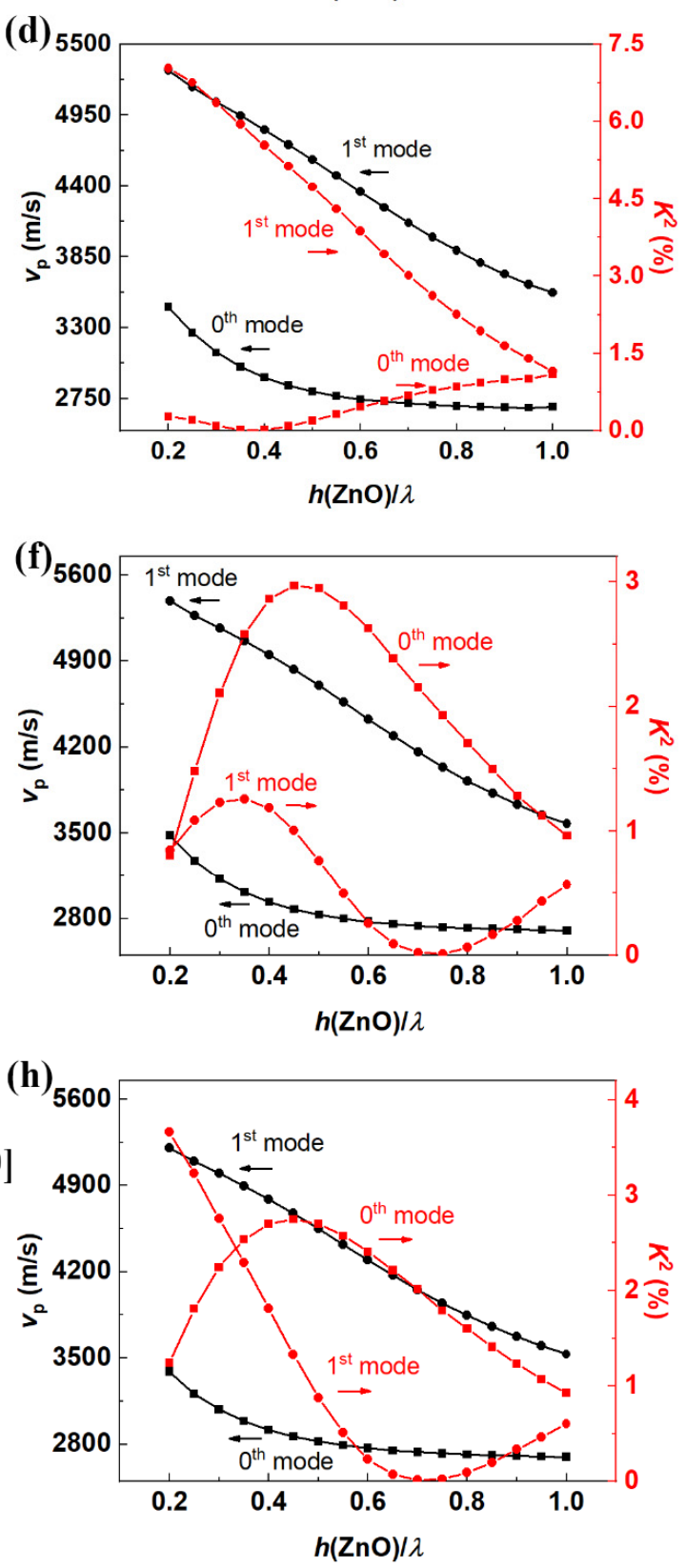

Figure 10. Four structures $(\mathbf{a}, \mathbf{c}, \mathbf{e}, \mathbf{g})$ where 0th Rayleigh-mode wave and 1st Rayleigh-mode wave (Sezawa-mode wave) are excited, and their corresponding $v_{\mathrm{p}}$ and $K^{2}$ dispersion patterns $(\mathbf{b}, \mathbf{d}, \mathbf{f}, \mathbf{h})$. 
At last, two modulations are combined, and the structure shown in Figure 10g are designed and studied. The simulation results are shown in Figure 10h in which all the $v_{p}$ values are close to the corresponding values in Figure $10 \mathrm{~b}$. Two curves of $K^{2}$ reflect the effects of the embedded IDT and the short-circuit thin film. According to the results described before, the short-circuit thin film only highly influences the Sezawa-mode, while the embedded IDT affects both two modes. Therefore, the values of $K^{2}$ of the 0th mode wave in Figure 10h are close to those in Figure 10f, because of the embedded IDT. In the meanwhile, the $K^{2}$ curve of the Sezawa-mode shows the characteristics of the $K^{2}$ curves in Figure $10 \mathrm{~d}$,f. The $K^{2}$ of the Sezawa-mode reaches about $3.7 \%$ at $h(\mathrm{ZnO}) / \lambda=0.2$, which is relatively large but much smaller than the maximum value of about $7 \%$.

\section{Discussion}

This work proves that SAW devices based on $\mathrm{ZnO}$ and $\mathrm{GaN}$ multilayers can be used in different applications. According to the results in this work, researchers can choose proper basic structures and modulations to realize various functions. Every structure's unique properties are valuable for diverse applications. The following are several examples.

The 0th-mode Love waves in the a- $\mathrm{ZnO} / \mathrm{a}-\mathrm{GaN}$ structure and the $\mathrm{a}-\mathrm{ZnO} / \mathrm{a}-\mathrm{GaN} / \mathrm{r}-$ sapphire structure are suitable for large-coupling devices, and the sapphire substrate can also improve the $v_{\mathrm{p}}$. Thanks to the special vibration state of Love-mode wave, these structures are proper for sensing systems in liquid environments. Meanwhile, if the 2DEG is prepared, programmable SAW sensors can be obtained.

The Sezawa-mode waves in the c- $\mathrm{ZnO} / \mathrm{c}-\mathrm{GaN} / \mathrm{c}$-sapphire structure and the $\mathrm{c}-\mathrm{ZnO} /$ $\mathrm{SiN}_{\mathrm{x}} / \mathrm{GaN}$ structure have the properties of high $v_{\mathrm{p}}$ and large coupling, so they are suitable for high-frequency and large-bandwidth SAW devices. Tunable devices based on these structures have larger absolute frequency shifts because of the higher basic operating frequencies. Short-circuit thin films can be added to further improve the $K^{2}$.

If fabricating high-frequency devices is the purpose, in addition to adopting structures with high $v_{\mathrm{p}}$, shortening the $\lambda$ is necessary. Devices with the $\lambda$ of $1 \mu \mathrm{m}$ or even shorter can be fabricated in reality according to the devices in the former research such as [12]. Even when the lithography reaches its limit, the new solution we proposed in our former work [36] can further shorten the $\lambda$ under the same critical resolution of lithography. Therefore, in accordance with the former research and the results in this work, the frequency higher than $10 \mathrm{GHz}$ can be achieved by the devices based on the structures in this paper.

\section{Conclusions}

This work systematically studies the basic properties of SAW devices based on $\mathrm{ZnO}$ and GaN multilayers. The structures including a-ZnO/a-GaN, a-ZnO/a-GaN/r-sapphire, $\mathrm{c}-\mathrm{ZnO} / \mathrm{c}-\mathrm{GaN}, \mathrm{c}-\mathrm{ZnO} / \mathrm{c}-\mathrm{GaN} / \mathrm{c}-\mathrm{sapphire}$, and $\mathrm{c}-\mathrm{ZnO} / \mathrm{SiN}_{\mathrm{x}} / \mathrm{GaN}$ are all simulated, and different orders of Rayleigh-mode waves, Love-mode waves, and Sezawa-mode waves are all considered. Results show the unique characteristics of each structure which can be applied in diverse fields. The range of the $v_{\mathrm{p}}$ from about $2700 \mathrm{~m} / \mathrm{s}$ to $6500 \mathrm{~m} / \mathrm{s}$ can be achieved, and devices based on $\mathrm{ZnO}$ and $\mathrm{GaN}$ multilayers can meet the requirement of the $K^{2}$ from about 0 to $7 \%$. This work has great reference value for research in the future, such as fabricating high-frequency and large-bandwidth SAW devices based on high-quality c-ZnO/c-GaN/c-sapphire, and realizing programmable SAW sensors based on a-ZnO/a-GaN/r-sapphire and 2DEG.

Author Contributions: Conceptualization, J.S.; methodology, J.S.; validation, J.S. and S.F.; data analysis, J.S., S.F., R.S. and H.X.; investigation, J.S.; resources, F.Z., C.S. and F.P.; data curation, J.S.; writing —original draft preparation, J.S.; writing — review and editing, J.S., S.F., F.Z., C.S. and F.P.; visualization, J.S. and R.S.; supervision, J.S. and S.F.; project administration, J.S. and S.F.; funding acquisition, F.Z., C.S. and F.P. All authors have read and agreed to the published version of the manuscript. 
Funding: This work was supported by the National Natural Science Foundation of China (Grant No. 52002205), China Postdoctoral Science Foundation (Grant No. 2020M680557), National Key Research and Development Program of China (Grant No. 2020YFB0408900) and Key Research and Development Program of Guangdong Province (Grant No. 2020B0101040002).

Data Availability Statement: The data presented in this study are available on request from the corresponding author.

Conflicts of Interest: The authors declare no conflict of interest.

\section{References}

1. Jeng, M.-J.; Sharma, M.; Li, Y.-C.; Lu, Y.-C.; Yu, C.-Y.; Tsai, C.-L.; Huang, S.-F.; Chang, L.-B.; Lai, C.-S. Surface acoustic wave sensor for c-reactive protein detection. Sensors 2020, 20, 6640. [CrossRef] [PubMed]

2. Constantinoiu, I.; Viespe, C. ZnO metal oxide semiconductor in surface acoustic wave sensors: A review. Sensors 2020, 20, 5118. [CrossRef] [PubMed]

3. Lo, X.-C.; Li, J.-Y.; Lee, M.-T.; Yao, D.-J. Frequency shift of a SH-SAW biosensor with glutaraldehyde and 3-aminopropyltriethoxysilane functionalized films for detection of epidermal growth factor. Biosensors 2020, 10, 92. [CrossRef] [PubMed]

4. Ruppel, C.C.W. Acoustic wave filter technology-a review. IEEE Trans. Ultrason. Ferroelectr. Freq. Control 2017, 64, 1390-1400. [CrossRef] [PubMed]

5. Takai, T.; Iwamoto, H.; Takamine, Y.; Fuyutsume, T.; Nakao, T.; Hiramoto, M.; Toi, T.; Koshino, M. High-performance SAW resonator with simplified $\mathrm{LiTaO}_{3} / \mathrm{SiO}_{2}$ double layer structure on Si substrate. IEEE Trans. Ultrason. Ferroelectr. Freq. Control 2019, 66, 1006-1013. [CrossRef] [PubMed]

6. Holm, A.; Sturzer, Q.; Xu, Y.; Weigel, R. Investigation of surface acoustic waves on $\mathrm{LiNbO}_{3}$, quartz, and $\mathrm{LiTaO}_{3}$ by laser probing. Microelectron. Eng. 1996, 31, 123-127. [CrossRef]

7. Look, D.C.; Farlow, G.C.; Reunchan, P.; Limpijumnong, S.; Zhang, S.B.; Nordlund, K. Evidence for native-defect donors in n-type ZnO. Phys. Rev. Lett. 2005, 95, 4. [CrossRef]

8. Yang, Q.; Wang, W.; Xu, S.; Wang, Z. Enhancing light emission of ZnO microwire-based diodes by piezo-phototronic effect. Nano Lett. 2011, 11, 4012-4017. [CrossRef]

9. Wang, T.; Wu, H.; Wang, Z.; Chen, C.; Liu, C. Improvement of optical performance of ZnO/GaN p-n junctions with an InGaN interlayer. Appl. Phys. Lett. 2012, 101, 161905. [CrossRef]

10. Luo, J.; Zeng, F.; Pan, F.; Li, H.; Niu, J.; Jia, R.; Liu, M. Filtering performance improvement in V-doped ZnO/diamond surface acoustic wave filters. Appl. Surf. Sci. 2010, 256, 3081-3085. [CrossRef]

11. Didenko, I.S.; Hickernell, F.S.; Naumenko, N.F. The experimental and theoretical characterization of the SAW propagation properties for zinc oxide films on silicon carbide. IEEE Trans. Ultrason. Ferroelectr. Freq. Control 2000, 47, 179-187. [CrossRef] [PubMed]

12. Fu, S.; Wang, W.; Qian, L.; Li, Q.; Lu, Z.; Shen, J.; Song, C.; Zeng, F.; Pan, F. High-frequency surface acoustic wave devices based on $\mathrm{ZnO} / \mathrm{SiC}$ layered structure. IEEE Electron. Device Lett. 2019, 40, 103-106. [CrossRef]

13. Harding, G.L.; Du, J. Design and properties of quartz-based Love wave acoustic sensors incorporating silicon dioxide and PMMA guiding layers. Smart Mater. Struct. 1997, 6, 716-720. [CrossRef]

14. Barie, N.; Stahl, U.; Rapp, M. Vacuum-deposited wave-guiding layers on STW resonators based on $\mathrm{LiTaO}_{3}$ substrate as Love wave sensors for chemical and biochemical sensing in liquids. Ultrasonics 2010, 50, 606-612. [CrossRef]

15. Matatagui, D.; Fontecha, J.; Fernandez, M.J.; Oliver, M.J.; Hernando-Garcia, J.; Sanchez-Rojas, J.L.; Gracia, I.; Cane, C.; Santos, J.P.; Horrillo, M.C. Comparison of two types of acoustic biosensors to detect immunoreactions: Love-wave sensor working in dynamic mode and QCM working in static mode. Sens. Actuator B Chem. 2013, 189, 123-129. [CrossRef]

16. Higashiyama, T.; Katsuyama, A.; Otori, H.; Kamimura, T.; Uehara, A.; Kainuma, M.; Takumi, R.; Kudo, Y.; Ebina, M.; Mochitate, K.; et al. Detection of cellular damage by hydrogen peroxide using SV40-T2 cells on shear horizontal surface acoustic wave (SH-SAW) sensor. Ultrasonics 2014, 54, 1430-1438. [CrossRef]

17. Wang, Y.; Zhang, S.; Xu, J.; Xie, Y.; Lan, X. Characteristics of surface acoustic waves in (1120) ZnO film/R-sapphire substrate structures. Sci. China Phys. Mech. Astron. 2018, 61, 024311. [CrossRef]

18. Emanetoglu, N.W.; Patounakis, G.; Liang, S.H.; Gorla, C.R.; Wittstruck, R.; Lu, Y.C. Analysis of SAW properties of epitaxial ZnO films grown on $\mathrm{R}_{-} \mathrm{Al}_{2} \mathrm{O}_{3}$ substrates. IEEE Trans. Ultrason. Ferroelectr. Freq. Control. 2001, 48, 1389-1394. [CrossRef]

19. Tjeung, R.T.; Maurya, D.K.; Yeo, L.Y.; Friend, J.R.; Kandasamy, S. ZnO/sapphire Based Layered Surface Acoustic Wave Devices for Microfluidic Applications. In Proceedings of the 2011 6th IEEE International Conference on Nano/Micro Engineered and Molecular Systems, Kaohsiung, Taiwan, 20-23 February 2011. [CrossRef]

20. Wang, Y.; Zhang, S.; Fan, L.; Shui, X.; Zhang, Z.; Wasa, K. Characteristics of surface acoustic waves excited by (112̄0) ZnO films deposited on r-sapphire substrates. IEEE Trans. Ultrason. Ferroelectr. Freq. Control 2013, 60, 1213-1218. [CrossRef]

21. Lan, X.; Zhang, S.; Fan, L.; Wang, Y. Simulation of SAW humidity sensors based on (11̄20) ZnO/r-sapphire structures. Sensors 2016, 16, 1112. [CrossRef]

22. Cui, J.; Duan, Y.; Wang, X.; Zeng, Y. Strain status in ZnO film on sapphire substrate with a GaN buffer layer grown by metal-source vapor phase epitaxy. Microelectron. J. 2008, 39, 1542-1544. [CrossRef] 
23. Hong, S.K.; Ko, H.J.; Chen, Y.; Hanada, T.; Yao, T. ZnO/GaN heterointerfaces and ZnO films grown by plasma-assisted molecular beam epitaxy on (0001) GaN/ $\mathrm{Al}_{2} \mathrm{O}_{3}$. J. Vac. Sci. Technol. B 2000, 18, 2313-2321. [CrossRef]

24. Zhao, B.; Yang, H.; Du, G.; Miao, G.; Zhang, Y.; Gao, Z.; Yang, T.; Wang, J.; Li, W.; Ma, Y.; et al. High-quality ZnO/GaN/ $\mathrm{Al}_{2} \mathrm{O}_{3}$ heteroepitaxial structure grown by LP-MOCVD. J. Cryst. Growth 2003, 258, 130-134. [CrossRef]

25. Parmenter, R.H. The acousto-electric effect. Phys. Rev. 1953, 89, 990-998. [CrossRef]

26. Rocke, C.; Manus, S.; Wixforth, A.; Sundaram, M.; English, J.H.; Gossard, A.C. Voltage tunable acoustoelectric interaction in GaAs/AlGaAs heterojunctions. Appl. Phys. Lett. 1994, 65, 2422-2424. [CrossRef]

27. Wixforth, A.; Scriba, J.; Wassermeier, M.; Kotthaus, J.P.; Weimann, G.; Schlapp, W. Surface acoustic-waves on GaAs $\mathrm{Al}_{\mathrm{x}} \mathrm{Ga}_{1-\mathrm{x}} \mathrm{As}$ heterostructures. Phys. Rev. B 1989, 40, 7874-7887. [CrossRef] [PubMed]

28. Rotter, M.; Ruile, V.; Wixforth, A.; Kotthaus, J.P. Voltage controlled SAW velocity in GaAs/LiNbO3-hybrids. IEEE Trans. Ultrason. Ferroelectr. Freq. Control 1999, 46, 120-125. [CrossRef] [PubMed]

29. Pedros, J.; Calle, F.; Cuerdo, R.; Grajal, J.; Bougrioua, Z. Voltage tunable surface acoustic wave phase shifter on AlGaN/GaN. Appl. Phys. Lett. 2010, 96, 123505. [CrossRef]

30. Li, R.; Reyes, P.I.; Ragavendiran, S.; Shen, H.; Lu, Y.C. Tunable surface acoustic wave device based on acoustoelectric interaction in $\mathrm{ZnO} / \mathrm{GaN}$ heterostructures. Appl. Phys. Lett. 2015, 107, 5. [CrossRef]

31. Bahamonde, J.A.; Kymissis, I. A Reconfigurable surface acoustic wave filter on ZnO/AlGaN/GaN heterostructure. IEEE Trans. Electron. Devices 2020, 67, 4507-4514. [CrossRef]

32. Su, R.; Fu, S.; Shen, J.; Chen, Z.; Lu, Z.; Yang, M.; Wang, R.; Zeng, F.; Wang, W.; Song, C.; et al. Enhanced performance of $\mathrm{ZnO} / \mathrm{SiO}_{2} / \mathrm{Al}_{2} \mathrm{O}_{3}$ surface acoustic wave devices with embedded electrodes. ACS Appl. Mater. Interfaces 2020, 12, 42378-42385. [CrossRef] [PubMed]

33. Stefanescu, A.; Muller, A.; Dinescu, A.; Konstantinidis, G.; Cismaru, A.; Stavrinidis, A.; Neculoiu, D.; Society, I.E.D. FEM Analysis of GaN Based Surface Acoustic Wave Resonators. In Proceedings of the 2011 International Semiconductor Conference, Sinaia, Romania, 17-19 October 2011. [CrossRef]

34. Goto, T.; Anderson, O.L.; Ohno, I.; Yamamoto, S. Elastic-constants of corundum up to 1825K. J. Geophys. Res. 1989, $94,7588-7602$. [CrossRef]

35. Zhang, Q.; Han, T.; Wang, W.; Hashimoto, K.; Chen, J. Surface Acoustic Wave Propagation Characteristics of ScAlN/diamond Structure with Buried Electrode. In Proceedings of the 2014 Symposium on Piezoelectricity, Acoustic Waves, and Device Applications, Beijing, China, 30 October-2 November 2014. [CrossRef]

36. Shen, J.; Luo, J.; Fu, S.; Su, R.; Wang, W.; Zeng, F.; Song, C.; Pan, F. 3D layout of interdigital transducers for high frequency surface acoustic wave devices. IEEE Access 2020, 8, 123262-123271. [CrossRef]

37. Salim, Z.T.; Hashim, U.; Arshad, M.K.M. FEM Modeling and Simulation of A Layered SAW Device Based on ZnO/128 ${ }^{\circ}$ YX $\mathrm{LiNbO}_{3}$. In Proceedings of the 2016 IEEE International Conference on Semiconductor Electronics, Kaula Lumpur, Malaysia, 17-19 August 2016. [CrossRef]

38. Muller, A.; Giangu, I.; Stavrinidis, A.; Stefanescu, A.; Stavrinidis, G.; Dinescu, A.; Konstantinidis, G. Sezawa propagation mode in $\mathrm{GaN}$ on $\mathrm{Si}$ surface acoustic wave type temperature sensor structures operating at GHz frequencies. IEEE Electron. Device Lett. 2015, 36, 1299-1302. [CrossRef]

39. Talbi, A.; Sarry, F.; Le Brizoual, L.; Elmazria, O.; Alnot, P. Sezawa mode SAW pressure sensors based on ZnO/Si structure. IEEE Trans. Ultrason. Ferroelectr. Freq. Control 2004, 51, 1421-1426. [CrossRef]

40. Fu, S.; Wang, W.; Li, Q.; Lu, Z.; Chen, Z.; Luo, J.; Shen, J.; Wang, R.; Song, C.; Zeng, F.; et al. High-frequency V-doped ZnO/SiC surface acoustic wave devices with enhanced electromechanical coupling coefficient. Appl. Phys. Lett. 2019, 114, 5. [CrossRef] 